\title{
USO DA TERRA E AS IMPLICAÇÕES AMBIENTAIS NO MUNICÍPIO DE AMÉLIA RODRIGUES-BA
}

\author{
Caio Vinicius da Silva de Carvalho Bacelar ${ }^{(a)}$, Israel Oliveira Junior ${ }^{(b)}$, Kezia Andrade dos \\ Santos $^{(\mathrm{c})}$,
}

(a) Graduando em Geografia, Departamento de Ciências Humanas e Filosofia, Universidade Estadual de Feira de Santana, e-mail caioviniciusbacelar350@gmail.com.

(b) Doutorando em Geografia, Instituto de Geociências, Universidade Federal da Bahia, e-mail: iojjunior@gmail.com.

(c) Bacharel em Geografia, Departamento de Ciências Humanas e Filosofia, Universidade Estadual de Feira de Santana, e-mail kezia_peniel@hotmail.com

Eixo: Uso e ocupação das terras e legislação ambiental

\begin{abstract}
Resumo
Por meio deste trabalho, objetivou analisar o uso e cobertura da terra no município de Amélia Rodrigues-BA, para identificar as implicações ambientais. Para a realização do mapeamento de uso e cobertura da terra foram aplicadas as geotecnologias, associados aos levantamentos de dados em campo e referências bibliográficas específicas. A interpretação visual das imagens do sensor Pleiades 1A, possibilitou vetorizar os principais usos da terra e feições originárias, para a construção do mapa na escala de 1/10000. Identificou-se que 12 classes caracterizam a cobertura da terra municipal, com ampla espacialização das agricultura mecanizada, lavoura e pastagem alternadas e pastagem. As atividades agropecuárias são fatores importantes que dão feições à paisagem municipal e implicam, fortemente, em estados de deterioração ambiental. As práticas mais comuns são as de queimadas e de desmatamento, que expõem os solos as intempéries, causam erosão, a distribuição de pequenas manchas de feições vegetais do bioma mata atlântica, resultante das implicações da relação sociedadenatureza, que ampliam a vulnerabilidade ambiental.
\end{abstract}

Palavras chave: Paisagem; Indicador ambiental; Geotecnologias; Estado ambiental.

\section{Introdução}

O debate sobre a degradação ambiental se tornou mais frequente na contemporaneidade, a partir da percepção sobre a problemática ambiental e a discussão em eventos científicos, trabalhos acadêmicos, convenções internacionais e outros. Os estudos sobre processos erosivos, impactos ambientais, contaminação dos solos, perda da diversidade das florestas tropicais ganharam mais notoriedade em razão da intensa antropização das paisagens resultante da expansão das atividades agropecuárias pautadas na racionalidade econômica ocidental (LEFF, 2009). Segundo Sánchez (2008), a degradação ambiental decorre das transformações adversas em processos, funções e componentes da paisagem, que alteram a 


\section{OS DESAFIOS DA GEOGRAFIA FÍSICA NA FRONTEIRA DO CONHECIMENTO \\ Instituto de Geociências - Unicamp \\ Campinas - SP \\ 28 de Junho à 02 de Julho de 2017}

qualidade ambiental de forma negativa. A degradação ambiental é originária das relações sociais, como as atividades relacionadas à agricultura, à pecuária, às indústrias, à mineração, quando a pressão exercida decorre em desequilíbrio e modificações em processos e formas do meio ambiente, que causam prejuízos à saúde humana, à sociedade, à economia, à biosfera, às condições estéticas e sanitárias, espaciais e outras (SÁNCHEZ, 2006).

Uma das possibilidades de aplicar o conhecimento geográfico é por meio de indicadores ambientais, pois são úteis para a avaliação de fenômenos, apresenta as tendências e os progressos de políticas, são objetivos no número de informações, a sua aplicabilidade pode ser de baixo custo e demandam pouco tempo para a análise dos fenômenos (MINISTÉRIO DO MEIO AMBIENTE, 2007). Os indicadores ambientais contêm informações quantificadas e qualitativas para comunicar sobre a realidade ambiental e possibilitar a compreensão sobre os cenários ambientais. Kraemer (2004) afirma que a aplicação dos indicadores ambientais deve estar associada aos métodos de produção e de consumo, refletir as intensidades de emissões e a utilização de recursos em um determinado tempo e de baixo custo operacional, para possibilitar a análise ambiental e projetar políticas.

Segundo Tomasoni (2008), o indicador é um conjunto de informações que pode se chegar próximo a realidade de um fenômeno que se objetiva avaliar. Sendo assim, os indicadores são utilizados por várias ciências (Biologia, Economia, Geografia, Sociologia e outras) e são passíveis de comprovação. A partir da aplicação de um indicador, pode-se descrever o estado de um determinado fenômeno estudado. Gomes (2000) define o indicador como uma estatística que se relaciona com a condição ou mudança do estado (ambiente) que se pretende estudar lhe dando informações e a partir disso descrever o fenômeno observado.

O uso e cobertura da terra é um indicador ambiental que possibilita avaliar as diferentes dimensões intrínsecas à paisagem, como as relacionadas à pressão e ao estado ambiental. A partir da aplicação dele identifica-se e interpreta-se as formas dos objetos, as atividades humanas predominantes, as práticas e técnicas utilizadas na apropriação do ambiente e as consequências resultantes subsidiam o planejamento ambiental e outros (OLIVEIRA JUNIOR, 2014).

Por meio desse trabalho, objetivou-se analisar as implicações ambientais decorrentes do uso da terra, a partir da aplicação de indicadores ambientais no município de Amélia Rodrigues-BA. O indicador uso e cobertura da terra foi selecionado na tentativa de identificar os estados da paisagem, sobretudo aqueles relacionados às atividades agrárias. As implicações ambientais são resultantes da pressão ambiental decorridas na relação sociedade-natureza. $\mathrm{O}$ desenvolvimento das atividades sociais decorre em alterações na paisagem, com consequências para os elementos que a constitui. $\mathrm{O}$ município de Amélia Rodrigues 


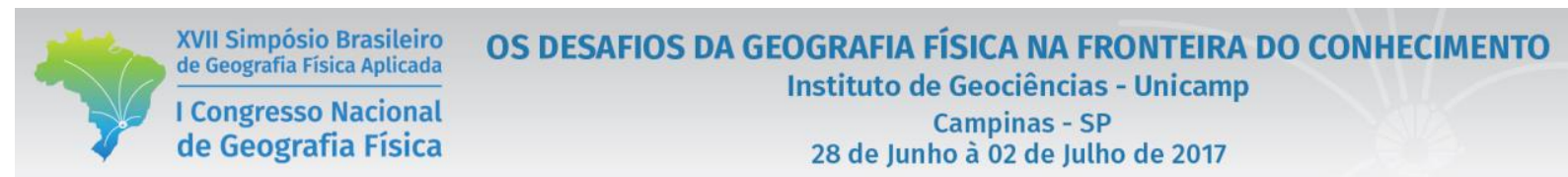

localiza-se no estado da Bahia e as principais vias de acesso para as terras municipais é a rodovia BR 324 (Salvador-BA - Feira de Santana-BA) na qual há um grande fluxo de pessoas, mercadorias e de capital (Figura 1). A cidade de Amélia Rodrigues encontra-se a 84 km de Salvador, a 24km de Feira de SantanaBA, e integra-se o território de identidade Portal do Sertão.

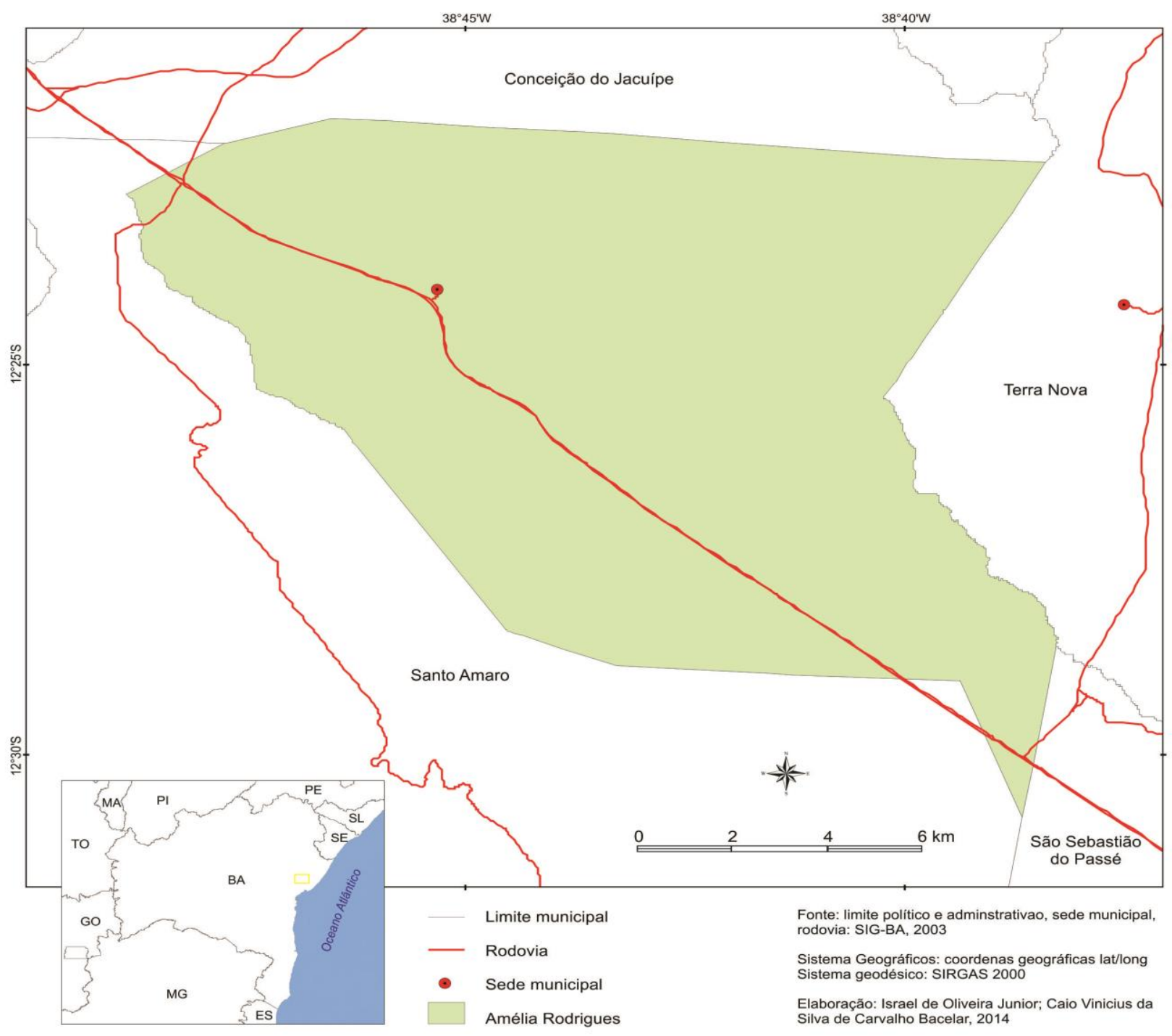

Figura 1 - Mapa de localização do Município de Amélia Rodrigues-BA.

\section{Materiais e Método}

Incialmente, para a realização desta pesquisa fez-se uma revisão bibliográfica para a fundamentação teórica, conceitual e metodológia da pesquisa, bem como para subsidiar a análise dos resultados. Foram analisados temas, como paisagem, degradação ambiental, indicadores ambientais, uso e cobertura da terra e a aplicação de geotecnologias no contexto da Geografia. 
Para a elaboração do mapa de uso e cobertura da terra, utilizou-se as técnicas de sistema de posicionamento global (GPS), sistema de informações geográficas (SIG) e sensoriamento remoto. Para o mapeamento de uso e cobertura da terra do município de Amélia Rodrigues, utilizou-se as imagens do sensor francês Pléiades 1A, disponibilizado pelo programa Google Earth Pró, com resolução espacial original de $50 \mathrm{~cm}$. Logo após o georeferenciamento e correção geométrica das imagens, análise de dados secundários (SIG-BA, 2003; BRASIL, 1982) e de campo, foram definidas as classes de uso e cobertura da terra e a identificação delas na imagem para, posterior, identificação e vetorização das classes e construção do mapa em escala cartográfica de 1/10000.

Foram selecionados 33 pontos de coletas de informações em campo relacionadas às pressões e estados ambientais, distribuídos pelo município para gerar uma diversidade de informações ambientais (físicas, biológicas e sociais). Os pontos de levantamento de dados em campo foram georreferenciados para posterior integração ao banco de dados SIG da pesquisa.

\section{Resultados e discussão}

O clima do município de Amélia Rodrigues é tropical úmido a subúmido com precipitação média anual de $1277 \mathrm{~mm}$. O período mais chuvoso é de abril a junho, apresentando uma temperatura média de $23,4^{\circ} \mathrm{C}$ (SUPERINTENDÊNCIA DE ESTUDOS ECONÔMICOS E SOCIAIS DA BAHIA, 2016). O território municipal é de 173,484 $\mathrm{km}^{2}$, constituído por uma estrutura geológica representada por arenitos, conglomerados, folhelhos, pertencentes ao grupo da Bacia Sedimentar Tucano-Recôncavo Sul (MILHOMEM et al., 2003). Assim, a estrutura litológica é sedimentar, além de anfibolitos, migmatitos e ortognaisses que são encontrados no setor noroeste do município.

As unidades geomorfológicas predominantes são constituídas por formas de dissecação e aplanamento embutidos e os tabuleiros interioranos. As formas de dissecação e aplanamentos embutidos possuem relevos planos ou ondulados abaixo do nível das regiões vizinhas, no qual apresenta como base arenitos, conglomerados e folhelhos. Por serem materiais relativamente frágeis aos agentes intempéricos pode ser submetido ao processo de aplanamento. Nos tabuleiros interioranos predominam as formas de relevo de topo plano, elaborados por rochas sedimentares, com altitudes relativamente baixas. Nota-se que o setor onde se encontra as rochas sedimentares se desenvolveu os tabuleiros.

Os solos principais encontrados na área de estudo são: o argissolo vermelho-amarelo distrófico, argissolo vermelho-amarelo eutrófico e vertissolos. Os vertissolos são encontrados nas formações de dissecação e aplanamentos embutidos, onde se encontram os monocultivos de cana-de-açúcar. Os principais canais de drenagem são: rio Jacuípe, rio Pojuca, rio Traripe e rio Seco. Em Amélia Rodrigues-BA, as águas dos rios 


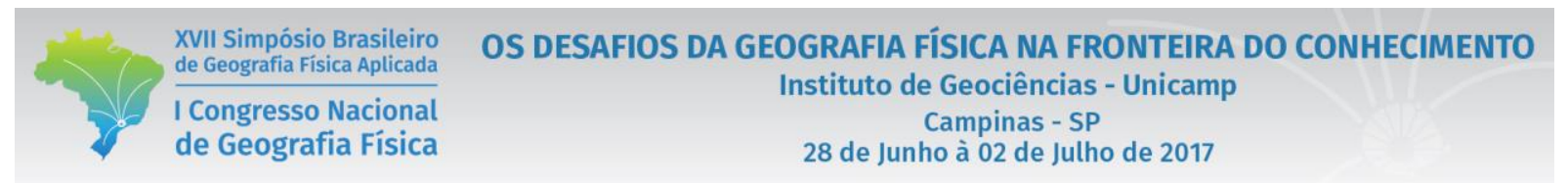

são utilizadas para as atividades de pecuária extensiva, sobretudo para a dessedentação animal, e para o escoamento dos rejeitos da produção de cana-de-açúcar. É necessário destacar que nenhum rio se encontra no espaço urbano.

O desenvolvimento das atividades agropecuárias, como a criação de gado e o cultivo da cana-de-açúcar, decorreu na supressão das feições vegetais, onde cerca de $80 \%$ das terras ocorrem as atividades agropecuárias, nas quais são criados bovinos, equinos, ovinos, galináceos e codorna e cultivados cana-deaçúcar, mandioca, laranja, feijão, milho, coco-da-baía e banana (IBGE, 2016), e o processo de urbanização. Como observado no mapa de uso e cobertura da terra de Amélia Rodrigues-BA (Figura 2), existem algumas manchas de floresta estacional e de floresta ombrófila no município e se apresentam de maneira descontínuas, devido às práticas de desmatamentos e de queimadas, como aquele que acontecem no desencadeamento das atividades de monocultura nos fins de safra.

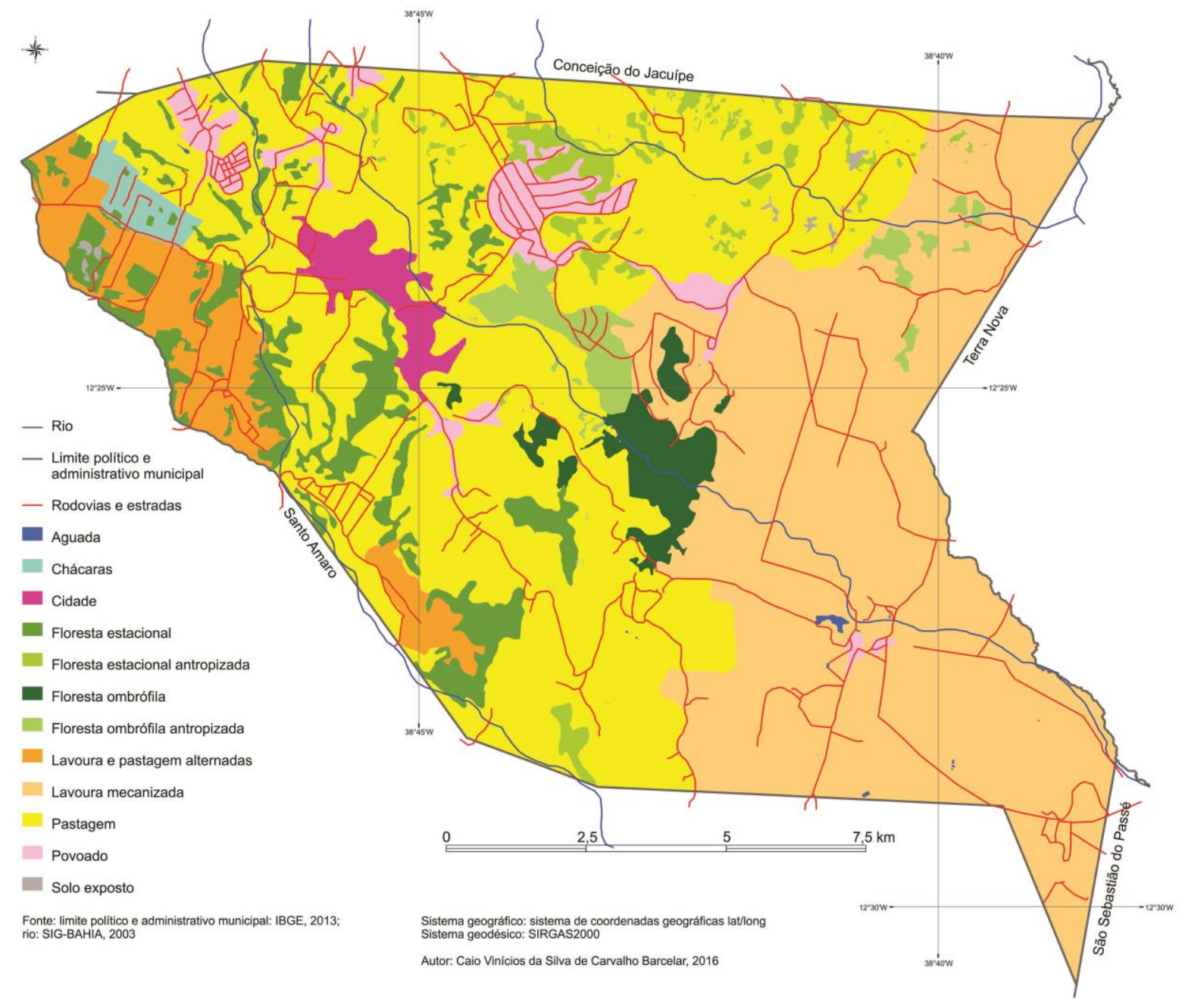

Figura 2- Mapa de uso e Cobertura das Terras - município de Amélia Rodrigues-BA. 
Há duas feições vegetais preponderantes no município, a floresta estacional e a floresta ombrófila, além de encontrar feições vegetais antropizadas decorrentes do avanço da pecuária e das atividades agrícolas (Figura 2). A Floresta Estacional localiza-se de maneira descontínua nos tabuleiros, próximo à sede do município, ela se encontra nos topos das vertentes e representa a maior parte das feições vegetais (Figura 2), distribuída em $1050 \mathrm{ha}$, cerca de $6 \%$ do território municipal.

Nas proximidades dos povoados, de áreas de lavoura e pastagem alternadas, e da lavoura mecanizada (cana-de-açúcar) a floresta estacional possui um grau elevado de antropização, a partir de práticas como o desmatamento, queimadas e de introdução do gado. Esta classe foi denominada de floresta estacional antropizada, que abrange cerca de $2 \%$ do município, equivalente a cerca de 400 ha (Figura 2). Nos ambientes de ocorrência da classe aludida, cria-se gado e desenvolve a lavoura da cana-de-açúcar, cultivos de mandioca, milho, coco-da-baía, banana e laranja.

A floresta ombrófila se concentra no compartimento geomorfológico formas de dissecação e aplainamentos embutidos. Essa classe reveste $2 \%$ da área do município (Figura 2), referindo a 420ha. A floresta ombrófila antropizada refere-se à feição vegetal com modificações na densidade, espécies e portes decorrentes das práticas agropecuárias. Ela encontra-se fragmentada e abrange cerca de $2 \%$ do município (Figura 2), referindo a 360ha.

As áreas antropizadas possuem uma extensão de 15.100ha, com cerca de 87\% da área do município, formadas pelas classes pastagem, lavoura e pastagem alternadas, lavoura mecanizada, chácaras, cidade e povoado, representando 40\%, 5\%,35\%, 1\%, 2\% e 3\%, respectivamente (Figura 2). A classe Aguada representa $0,1 \%$ da área de estudo (Figura 2).

Foram verificados nos estudos de campo a supressão da vegetação primária, das matas ciliares, solapamento e algumas áreas de solo exposto. A antropização das feições vegetais no município, por meio do desmatamento para fins de produção agrícola e criação de gado, pode agravar e acelerar os processos erosivos no solo. A Empresa Brasileira de Pesquisa Agropecuária (EMBRAPA, 2011) afirma que além do desmatamento, a utilização inadequada do solo para uso agrícola acelera os processos erosivos e tem como consequência, o assoreamento dos canais de drenagem. Nota-se que no município de Amélia Rodrigues-BA, existe presença de voçorocas em decorrência do escoamento de água na encosta dos relevos, associado ao desmatamento para a construção das moradias. Magalhães (2001) afirma que a voçoroca ocorre em locais que apresentam solos e/ou rochas friáveis, com trilhas para o gado, estradas, utilização inadequada do solo, com a retirada da cobertura vegetal, abertura de valetas e loteamentos, áreas com declividades altas, solos arenosos com baixa coesão, forma e comprimento da vertente e em locais de clima úmido, tropical e temperado sem estação seca. 
Em Amélia Rodrigues-BA é comum o aparecimento de processos erosivos devido à estrutura morfológica e composição sedimentar da formação barreiras (CPRM, 2015). Segundo o Serviço Geológico Brasileiro (2015), o material friável faz com que o terreno seja suscetível a deslizamentos de terra, sulcos, ravinas, voçorocas, decorrentes do escoamento superficial da água pluvial e do despejo de esgoto doméstico direto na encosta desprotegida de vegetação. Aliado a isso, as atividades agropecuárias, a partir do desencadeamento de práticas como o desmatamento, expõe os solos aos agentes intempéricos materializando a degradação. A ação humana é preponderante para o agravamento dos processos erosivos, contribuindo na aceleração da transformação da paisagem ameliense.

No campo foram encontradas extensas terras com solos expostos causados por atividades agropecuárias que provocam solapamento e compactação do solo pela ação do pisoteio do gado bovino. As superfícies de solo exposto se apresentam em descontinuidade no município e recobrem uma área total de $0,3 \%$, ou seja, um total de 32,5ha. As pastagens às margens dos rios geram estados de deterioração ambiental, como os encontrados no rio Cabuçu. Neste último, notou-se a presença de solos expostos e o pisoteio do gado bovino próximo às margens, que podem contribuir para intensificação da erosão.

Outra ação prática relacionada às atividades agrárias verificada em campo foi as queimadas. É muito comum elas acontecerem para o desencadeamento do monocultivo de cana-de-açúcar, para facilitar a colheita do produto. Porém, além da degradação do solo, traz alguns transtornos à população de Amélia Rodrigues-BA, como o transporte das cinzas ao espaço urbano, pela ação do vento. Em áreas de ocorrência do bioma mata atlântica, as queimadas das feições vegetais podem destruir a matéria orgânica e empobrecer o solo (HAMMES, 2002).

A partir do que foi observado em campo no mapa de uso e cobertura da terra, notou-se uma intensa antropização no município de Amélia Rodrigues. $\mathrm{O}$ avanço da atividade agropecuária e da urbanização tem causado problemas ambientais, como a exposição de solos aos agentes intempéricos, nos quais pode causar erosão e empobrecer o solo e provocar perdas de culturas e baixa produtividade agrícola, avanço de voçorocas e deslizamentos de terra. Grande parte das feições vegetais está com algum grau de antropização (trilhas de gado, desmatamento, solo exposto) e vários hectares de florestas deram lugar às pastagens contribuindo ao aceleramento dos processos erosivos. Há canais de drenagem, como o rio Cabuçu, que apresentam processo de solapamento de margens, demonstrando a quão nociva é a ação humana para a paisagem na intenção de transformá-la em recurso.

A pecuária extensiva é uma das principais atividades econômicas do município de Amélia Rodrigues-BA ocupando vários hectares. São criados os gados bovinos, equinos, suínos, ovinos, caprinos e galináceos (codorna e galinha). É notável que o gado bovino represente mais da metade de toda atividade pecuarista 
do município e suas carnes são vendidas em todos os mercados e açougues da sede e dos distritos do município. A criação de galináceos, em sua maioria, é para a produção de ovos de galinha e de codorna. As atividades agrícolas preponderantes são concernentes à agricultura irrigada, de subsistência e mecanizada. São produzidos através da agricultura irrigada e de subsistência a banana, coentro, mandioca, milho, amendoim, coco da baia e laranja. A agricultura mecanizada é notada pela vasta plantação de canade-açúcar, às margens da rodovia BR-324 desde o pedágio até a divisa com o município de Terra NovaBA.

\section{Considerações finais}

As atividades agropecuárias são as que mais causam transformação da paisagem do município e foram identificadas as implicações ambientais provocadas pelas pressões ambientais mais atuantes, como a agricultura e a pecuária. Essas duas atividades são as principais responsáveis pela ocorrência de solos expostos, compactação e erosão dos solos, solapamento de margens dos rios, perda de matéria orgânica provocada pela ocorrência de queimadas nos fins de safra da cana-de-açúcar.

Outro fator observado em campo é que o material sedimentar que recobre o município é friável, pouco coeso, poroso e é arenoso e argiloso e pouco resistente aos agentes intempéricos e que aliado ao intenso uso da terra que exercem como pressões ambientais o desmatamento aumenta a possibilidade de ocorrência dos processos supracitados e evidencia a importância da cobertura vegetal para a manutenção do equilíbrio ambiental.

Como verificado neste estudo, as formas de produzir no município convergem para práticas exploratórias, que resultam em desequilíbrios ambientais, porque transformam o patrimônio ambiental em recurso, objeto de lucro. Com isso, repensar sobre as técnicas e práticas à luz da legislação ambiental poderá reverter a generalização da degradação ambiental no município de Amélia Rodrigues-BA.

\section{Bibliografia}

BRASIL, Ministério das Minas e Energia. Projeto RADAMBRASIL: Folha SD.24 Brasília; geologia, geomorfologia, pedologia, vegetação e uso potencial da terra. Rio de Janeiro: Ministério das Minas e Energia, 1982.

EMPRESA BRASILEIRA DE PESQUISA AGROPECUÁRIA. Controle dos Processos Erosivos Lineares (ravinas e voçorocas) em Áreas de Solos Arenosos. Jaguariúna: EMBRAPA, 2011.

GOMES, M. L.; MARCELINO, M. M.; ESPADA, M. G. Proposta para um sistema de indicadores de desenvolvimento sustentável. Lisboa: Graf \& Lito, 2000.

HAMMES, V. S. Erosão: Um indicador de impacto ambiental. Jaguariúna: EMBRAPA, 2002.

IBGE. Pesquisa Pecuária Municipal, 2016. Disponível em < http://www.ibge.gov.br >. Acesso em: 20 fev. 2016. 
KRAEMER, M. E. P. Indicadores Ambientais como Sistema de Informação. In: Encontro Nacional de Engenharia de Produção, 24. (ENEGEP), 2004, Florianópolis. Anais... Florianópolis: ABEPRO, 2004. Disponível em < http://www.abepro.org.br/biblioteca/ENEGEP2004_Enegep1002_0087.pdfpdf >. Acesso em: 1 mar. 2014.

LEFF, H. Ecologia, capital e cultura: a territorialização da racionalidade ambiental. Petrópolis: Vozes, 2009.

MAGALHÃES, R. A. Erosão: definições, tipos e formas de controle. In: Simpósio Nacional de Controle de Erosão, 7. 2001, Goiânia. Anais... Goiânia, SNCE, 2001. Disponível em < http://www.labogef.iesa.ufg.br/links/simposio_erosao/articles/T084.pdf >. Acesso em: 1 mar. 2014.

MILHOMEM, P. S.; MAMAN, E. J.; OLIVEIRA; F. M. Bacias sedimentares brasileiras: bacia do Recôncavo. Aracaju: Phoenix, 2003.

MINISTÉRIO DO MEIO AMBIENTE. Indicadores Ambientais, 2007. Disponível em: <http://www.mma.gov.br> Acesso em 18 abr. 2016.

SÁNCHEZ, Luis Enrique. Avaliação de impacto ambiental: conceitos e métodos. São Paulo: Oficina de Textos, 2006.

SERVIÇO GEOLÓGICO DO BRASIL. Ação emergencial para delimitação de áreas em alto e muito alto risco a enchentes, inundações e movimentos de massa: Amélia Rodrigues. Distrito Federal, DF: CPRM, 2015.

SISTEMA DE INFORMAÇÕES GEOREFERENCIADAS- SIG-BAHIA. Sistema de Informações sobre Recursos Hídricos- SIRH. Superintendência de Recursos Hídricos. Salvador, 2003.

TOMASONI, M. A. Análise das transformações socioambientais com base em indicadores para recursos hídricos no cerrado baiano: o caso da bacia hidrográfica do Rio de Ondas / BA. Tese (Doutorado em Geografia) Programa de Pós-graduação em Geografia, Universidade Federal de Sergipe, Aracaju, 2008 